BLS 35, No 1 2009. DOI: http://dx.doi.org/10.3765/bls.v35i1.3598

(published by the Berkeley Linguistics Society and the Linguistic Society of America)

\title{
English Adjectives Expressing "Type-Anaphora" in Indefinite Noun Phrases
}

\author{
TINE BREBAN \\ Research Foundation-Flanders and K.U.Leuven (University of Leuven)
}

\section{Introduction}

The analysis put forward in this article is framed within the current functional and cognitive approaches to the English noun phrase (henceforth NP). These analyses share the tenet that the main function of NPs is to denote entities and make them available as discourse topics, i.e. referents, for speaker $(\mathrm{S})$ and hearer $(\mathrm{H})$ to talk about (see e.g. Bache 2000:159). Specifically in Cognitive Grammar (Langacker 1991), a referent is conceived of as an instance of a type, e.g. Peter's cat denotes one specific instance of the type cat, the one that belongs to Peter. In order to turn entities into discourse topics, Langacker argues that $\mathrm{S}$ and $\mathrm{H}$ have to be able to establish joint mental contact or "coordination of reference" with them:

\footnotetext{
the speaker $(\mathrm{S})$ and hearer $(\mathrm{H})$ who jointly form the ground $(\mathrm{G})$, face the task of coordinating their mental reference to some instance $t_{i}$ of type $\mathrm{T}[\ldots]$. When both $\mathrm{S}$ and $\mathrm{H}$ make mental contact with $t_{i}$, full coordination of reference is achieved (Langacker 1991:91, see also Diessel 2006).
}

Information about the identification of the instance is conveyed in the NP by determiners. These divide into two basic types: definite determiners, e.g. definite article the, possessives, demonstratives, and indefinite ones, including the indefinite article $a$, some, zero article, every, no. While definite determiners indicate that the instance is identifiable, indefinite determiners have traditionally been defined negatively as signalling non-identifiability of the instance. Recent cognitive approaches (Langacker 1991, 2004; Gundel et al. 1993; Davidse 2004) have amended this interpretation of indefinite determination and drawn attention to the positive cognitive processes involved. They argue that indefinite determiners signal that although the identity of the instance denoted is presumed unknown, the type which it instantiates is identifiable - Gundel et al. (1993:275) characterize the cognitive state required by indefinite determination as "type-identifiability". This means concretely that the $\mathrm{H}$ can establish mental contact with the instance as 


\section{English Adjectives Expressing "Type-Anaphora"}

'an instance of this type'. That is, indefinite determiners denote unidentifiability of the instance but identifiability of the type.

In this paper, I will specifically be concerned with a particular mechanism of identification in the NP, that of phoric relations. These are identificational relations between the NP and another discourse referent (Martin 1992:82), called its "antecedent". ${ }^{1}$ The prototypical phoric relation is co-referentiality signalled by definite NPs: the referent of the NP and the antecedent are one and the same entity, e.g. in A nurse brought me some bread and coffee, but the bread was stale and the coffee tasted of soap (Macmillan English Dictionary 2002:1486), the bread is identified as the bread mentioned earlier, in the NP some bread. ${ }^{2}$ In examples such as this one, the relation of co-referentiality is expressed only by the definite article the. Alternatively, a strategy can be used to lexically instruct the $\mathrm{H}$ to set up a relation of co-referentiality, that is addition of an adjective which functions as a secondary determining element or 'postdeterminer' to the existing definite article and which expresses 'identity of reference', e.g.,

(1) If a house sells for 150,000 dollar and the owner pays a 6 percent brokerage fee, lenders don't care. But if the same house sells for 146,000 dollar, [...] (CB) ${ }^{4}$

100 Percent Philosopher Alan Watts once said that the sun would not be "bright" were it not for human eyes; thorns would not be "prickly" if skin were not soft; rocks would not be "hard" or "heavy" if muscles did not exist; and so on. "Bright", "prickly", "hard", and "heavy" are

\footnotetext{
${ }^{1}$ Martin (1992:98) introduces the terms "phoric" and "phoricity" as a cover term for the traditional relations of anaphora, in which the antecedent is found in the preceding text, cataphora, in which it is part of the following discourse, and other specific types of phoric relations such as exophora and homophora (see Halliday and Hasan 1976:31f). I use the term antecedent as cover term for antecedents in the strict sense as well as 'postcedents,' as the former clearly constitute the prototypical case.

${ }^{2}$ It has been argued that the definite article carries co-referentiality as a default implicature concerning the identification of the instance (e.g. Lyons 1999).

${ }^{3}$ The prototypical use of adjectives in the NP is to attribute a lexically specified property to the denoted instance. This is the attribute use as in The girl was wearing a very pretty blue ribbon in her hair $(C B)$. Some adjectives have a different use in the NP as secondary determiners or postdeterminers (Halliday 1994, Sinclair et al. 1990, Breban 2008a). Their function is to supplement the information given by the existing determiner in order for $\mathrm{S}$ and $\mathrm{H}$ to achieve joint mental contact. Secondary determiners do not convey a property but a more schematic concept such as 'identity of reference,' 'arbitrariness of reference' (women of a certain age (CB)), 'actualization of the instance' (a possible agreement $(C B)$ ). Structurally, they cannot be graded by degrees of comparison or submodifiers such as very, rather, quite, e. g. women of a *more/most/rather certain age, nor do they allow alternation with predicative construal, e.g. women of *an age which is certain. They typically occupy the position directly following the determiner in the NP string: women of a certain advanced age vs. *women of an advanced certain age and the identical three boys vs. *the strong three boys.

${ }^{4}$ The examples marked 'CB' are extracted from the COBUILD corpus, which is a 56 million word selection of the Bank of English that can be accessed via the Collins WordbanksOnline service, and reproduced here with the kind permission of HarperCollins Publishers.
} 
definable only by reference to our own senses. A century earlier Ralph Waldo Emerson arrived at the identical idea. We habitually attribute too much to the world, he observed, and not enough to ourselves. (CB)

While co-referentiality is the main phoric relation that has been discussed in the literature so far, Davidse (1999:228, 2001) put forward the hypothesis that it is also possible for a postdeterminer to express "type-anaphora", i.e. phoric identification of the type instantiated, in indefinite NPs. Take for example,

(3) It was alleged he struck one prison officer with a pipe and hit another officer on the head with his fist. (CB)

(4) If you have problems once you arrive at the cottage, the agency may be able to move you to a different house or solve the difficulty; (CB)

In these examples, the adjectives other and different function as postdeterminers to the indefinite article. They convey that the identity of the instantiated type, which is presented as known to $\mathrm{H}$ by the indefinite determiner, is phorically retrievable in the same way as the identity of the instance itself was in definite NPs with postdeterminers same and identical in (1) and (2). Davidse (1999:288, 2001) does not further develop her hypothesis, nor has it been taken up in other research.

The aim of this paper, is to substantiate, further develop and illustrate Davidse's notion of type-phoricity on the basis of a detailed corpus studies of nine adjectives that were found to have a postdeterminer use expressing type-anaphora in Breban and Davidse (2008), i.e. other, different, additional, further, new, fresh, similar, comparable and identical. ${ }^{5}$ I will provide a more detailed definition of type-phoricity (section 1.1) and present a fine-grained analysis of the semantics and typical uses of the nine adjectives expressing type-phoricity (sections 1.2, 1.3, and 1.4). Section 2 sums up the main arguments and proposes some theoretical generalizations.

\section{Corpus Studies of Nine Adjectives Expressing Type-Phoricity in NPs}

The following discussion is based on the qualitative analysis of contemporary corpus material from the 56 million words portion of the Bank of English (1995 until present) which can be accessed via the Collins WordbanksOnline service. The data samples used for the present paper consist of 400 examples per adjective extracted by using the adjective itself as query (see Breban 2002, 2006) for all adjectives except other, new and fresh. For other, an equivalent set of 400 random data was compiled using 'another or other' as query (also Breban 2002, 2006).

\footnotetext{
${ }^{5}$ Breban and Davidse (2008) give, on the basis of corpus investigation, an overview of the main adjectives that are used as postdeterminers supplementing the indefinite article in present day English.
} 


\section{English Adjectives Expressing "Type-Anaphora”}

For fresh and new, the discussion is based on new extractions of 100 examples made using the more specified queries 'a fresh', 'a new'.

\subsection{Type-Phoricity}

Type-phoricity means that the instantiated type, e.g. the type officer in (3) reproduced here as (5), can be identified on the basis of a phoric relation of identity.

(5) It was alleged he struck one prison officer with a pipe and hit another officer on the head with his fist. (CB)

In other words, type-phoricity means that the type is already present in the discourse or the discourse situation and postdeterminers such as other give the instruction for $\mathrm{H}$ to retrieve the type from this earlier mentioned instance. More specifically, the type is present in the form of other instances, the 'one prison officer' in (5) or 'the US' in (6).

(6) Mr Rosbrook said he was attracted to MBE because it was a unique concept with proven success in the US and other countries. (CB)

When postdeterminers such as other in (5) and (6) express type-phoricity, they set up a phoric relation with an antecedent NP but instead of instructing $\mathrm{H}$ to retrieve the identity of the instance itself (i.e. co-referentiality), they convey that the relation of identity does not pertain to the actual instance but to the type it instantiates. The semantics of type-phoricity can be paraphrased as create 'a new/different instance of the same type as the antecedent instance'. Typephoricity thus constitutes a complex phoric relation combining phoric identity on the type-level with phoric non-identity on the instance-level.

As I will show in the next sections, the different postdeterminers that express type-phoricity allow the $\mathrm{S}$ to express slightly different meanings with regard to the type to be identified. Some postdeterminers (other, different, additional, further, new and fresh) merely signal identity between the type descriptions of the NP and the antecedent NP, e.g. officer in (5). Postdeterminer other also has a second meaning, in which it sets up a phoric relation and indicates that the new NP provides the "name" for the type, e.g. in (6) the noun countries lexicalizes the type instantiated by the antecedent NP the US. The postdeterminers similar, comparable and identical, finally, instruct $\mathrm{H}$ to "enrich" the type description with information from the context. In (7), for instance, the type satellite has to be enriched with the information provided in the restrictive relative clause that could act as an early warning system for Earth-bound comets, rather like spy satellites that spot the exhausts of intercontinental ballistic missiles.

(7) The ISO satellite, launched yesterday by Ariane 4 rocket, is as big as a 50-seat coach, and weighs 2.5 tonnes. [...] Professor Roger Bonnet of the European Space Agency believes ISO might become a blueprint 
Tine Breban

\begin{abstract}
for a network of similar satellites that could act as an early warning system for Earth-bound comets, rather like spy satellites that spot the exhausts of intercontinental ballistic missiles. (CB)
\end{abstract}

I will discuss these three semantic subtypes in turn in sections 1.2 to 1.4 respectively. ${ }^{6}$

\title{
1.2. Postdeterminers Expressing Basic Phoric Retrieval of the Type
}

The postdeterminer that is most frequently used to express type-phoricity is other. When other combines with the indefinite article, an and other are orthographically a single unit, another (see (5)). Semantically, other focuses on the relation of non-coreferentiality between the new instance and the earlier mentioned instance. For example, in (5) the officer is not the prison officer mentioned earlier. Huddleston and Pullum (2002:391) point out that postdeterminer (an)other has two submeanings. In examples such as (8), other has an alternative meaning paraphrasable as 'a different', 'not the same'.

(8) Soviet President Mikhail Gorbachev today removed the general in charge of the army and replaced him with another general who refused to deploy his troops in support of the attempted coup. (CB)

In examples such as (9), other expresses an additive meaning paraphrasable as 'an additional' or 'a new'.

(9) You can eat walking along the street, you know, you can stuff your face with hot dogs and then follow them by a giant coke and then perhaps another hot dog. (CB)

In these examples, (an)other introduces a new instance in a series of instances (In the case of two instances, i.e. one antecedent instance and the new instance, another can be paraphrased by 'a second' (see also OED s.v. another)). Of these two, the additive meaning is the most frequent one in my corpus sample. (see also Macmillan 2002 s.v. another). In contrast to the alternative meaning, the additive meaning often does not require the presence of a previous instantiation in the text, rather it implies previous instantiation, i.e. the instance is 'a new instance of a type of which $\mathrm{S}$ and $\mathrm{H}$ know previous instances' or 'previous instantiations are part of the knowledge $\mathrm{S}$ and $\mathrm{H}$ share'.

\footnotetext{
${ }^{6}$ I would like to emphasize that all three types of postdeterminers express that the type is available in the discourse. They are hence different from secondary determiners such as predeterminer such and postdeterminers usual, kind of, which instruct the $\mathrm{H}$ to "create" a type, e.g.
}

(i) We don't need such a man here (Lyons 1999:40)

(ii) Then there will be the usual Christmas lunch. (CB) (Breban 2008b) 


\section{English Adjectives Expressing "Type-Anaphora”}

(10) On talkback radio and in letters to the editor Leunig was accused of laying yet another guilt-trip on working mothers. (CB)

In (10), the fact that a series of instances is involved is also signalled by the adverbial yet. Finally, I should be noted that The additive meaning has a specialized variant in which (an)other does not signal a new instance being added but the addition of a quantified set to previous sets:

(11) McClellan is pulling no punches when he talks of his knockout record. He dispatched 55 opponents to the canvas as an amateur, followed by another 29 pro victims in the ring and three outside it. (CB)

In (11) the NP another 29 pro victims adds a new set of 'victims' to a previously mentioned set, 55 opponents. The other adjectives expressing type-phoricity as such, different, additional, further, new and fresh are less frequently used as postdeterminers than other (see Davidse and Breban 2003; Breban 2008c). Compared to other, their meaning is typically more specific; they express either the alternative or the additive meaning or another related meaning.

Postdeterminer different is restricted to the alternative meaning, i.e. "not the same instance', and does not express the additive meaning, e.g. (12).

(12) If you have problems once you arrive at the cottage, the agency may be able to move you to a different house or solve the difficulty; (CB)

One context in which different is preferred over other to convey the alternative meaning is formed by data in which the antecedent is part of the discourse situation (exophoric reference), as in (13).

(13) Are you in any way worried about going to Germany? Not just about doing the programming but just going across to Germany and living in a different country" $(\mathrm{CB})$

The antecedent of a different country is the country that the $\mathrm{H}$ is living in at the moment of the utterance.

The postdeterminers additional and further only express the additive meaning: they indicate the addition of a new instance to a series of instances, e.g. (14) and (15).

(14) So far, he'll be on the ballot in Kentucky, Wyoming, Tennessee, Utah, Delaware and Maine. On Friday, Perot plans to address supporters in six additional states simultaneously by satellite television, both to mark the completion of petition gathering in those states and to demonstrate his idea of an electric town hall. (CB) 
Tine Breban

(15) CONNOLY MOSCOW A further indication of the split within the Soviet communist party has come with the sharp criticism by the Soviet Foreign Minister Shevernadze, of certain senior army officers. (CB)

Like other, both adjectives can also be used when the additive relation pertains to quantified sets rather than instances, as illustrated in (16) and (17).

(16) Rolf Borjesson, chief executive of PLM, the Swedish packaging company, will succeed David Lyon as managing director and chief executive in July. Mr Lyon will continue as a director for an additional 12 months. (CB)

(17) NEWSDESK TOMLINSON MIAMI The diplomatic tension between Cuba and Spain is rising, following the incident on Friday when a further nine Cubans broke into the Spanish embassy in Havana. They said they were seeking sanctuary, like nine other Cubans already in the building. (CB)

In contrast to other, however, their strongest semantic emphasis is on the quantitative aspect of the additive meaning: they always invoke a sense of accumulation. Because of this emphasis, further and additional in NPs with uncount and plural count head, (18) and (19) respectively, are paraphrasable by 'more'.

(18) Establish whether traffic delays are expected on the day anywhere along the route to the place of marriage. If this is the case, allow additional time for travel. (CB)

(19) The result was dampened by news this morning that the city had slipped another three-million pounds towards a deficit with the cancellation of the land deal. That brought a warning from Mr Rimmer that further job cuts might be necessary. (CB)

The data also reveal that further frequently occurs in NPs with singular head noun; in particular in binominal NPs of the type a further sign, example, round of N, e.g. (20).

(20) A statement issued from the Foreign Office in the last few minutes reads as follows: "We totally regret the Iraqi note as a further example of blatant Iraqi disregard for international law." (CB)

The postdeterminers new and fresh can express both the alternative and the additive submeanings, but also convey yet another meaning that incorporates elements of both meanings, replacement of the antecedent instance by the denoted instance, e.g. 


\section{English Adjectives Expressing "Type-Anaphora”}

(21) The European Court case arose after Bosman, a Belgian player with RFC Liege completed a two-year contract. He was offered a new deal at a quarter of his previous salary and, when he denied, was prevented from leaving by the price the club put on his head. (CB)

(22) Family busses on the move By motoring writer STUART SCOTT People movers, multi-passenger vehicles, mini busses, people carriers whatever the name, they're on the way back. A fresh breed of family wagon is about to take Australia by storm as new makers enter the field with fresh designs at attractive prices. (CB)

In example (21), new implies both that the deal denoted is "an additional" deal following the two-year contract and that it is ipso facto "a different" deal. Yet, the most central idea that new conveys seems to me that the new deal replaces an earlier deal, viz. the antecedent referent the two-year contract. The replacement meaning moreover occurs with a typical range of collocations, head nouns denoting something that is typically replaced, such as a fresh/new generation of N, a fresh/new range of $\mathrm{N}$, a fresh/new breed of $\mathrm{N}$, a fresh/new series, see (22). Similar to the additive meaning, in most of the data in which new expresses the replacement meaning, the antecedent is not lexically present, but it is considered part of the shared knowledge of $\mathrm{S}$ and $\mathrm{H}$ or its existence is merely implied. Take for instance (23),

UGANDA REBELS A Ugandan government newspaper has reported that a number of rebels belonging to the Ugandan People's Army (UPA) have been killed following a new offensive in Serere and Kasilo counties in the East of the country. (CB)

For new, the replacement meaning is clearly the most frequent one. Fresh, by contrast, most frequently conveys the additive meaning illustrated in (24).

(24) Good morning. The allied forces have begun a fresh wave of bombing raids against Iraq and occupied Kuweit. (CB)

Like the replacement meaning, the additive meaning of fresh occurs in a particular set of binominal collocates such as a fresh wave/bout/round of $\mathrm{N}$.

\subsection{Postdeterminer Other Naming the Type of the Antecedent}

In some corpus examples, the function of other is not only to introduce or add a new instance of the same type of the antecedent. Other also "names" the type. That is to say, the NP with other actually supplies the lexicalization of the type. Two further subtypes can be distinguished. In a first set of examples, the antecedent NP does not have a (separate) type description. This is amongst others the case when the antecedent head noun refers to the instance as such and not to the 
Tine Breban

type it instantiates, as in (25), or when the antecedent is a stretch of text (a "text referent" (Willemse 2005:93f)), as in (26).

(25) With the Columbia grounded for the time being, NASA is moving ahead with launch plans for two other shuttles. (CB)

(26) The Australian Medical Association president yesterday claimed an increase in thyroid cancer in Australia was directly linked to nuclear tests. However, one of the authors of a new study was more cautious saying simply that there was no other reasonable explanation for the increased cases. (CB)

In a second set of examples, the NP with other "changes" the type and provides a new, unexpected type description, which often conveys the S's opinion about or interpretation of the categorization/description of the instance, e.g. (27).

(27) Today Gen Smith travels to Bosnian Serb headquarters in nearby Pale to resolve the airport stand-off and other sticking points between the United Nations and the Serbs. (CB)

In the literature, this process has been called "reclassification" (Salmon-Alt 2001) or "redescription" (Modjeska 2003).

\subsection{Postdeterminers Enriching the Type Description}

The postdeterminer uses of the adjectives similar, comparable and identical do not focus on the fact that a different or an additional instance is being denoted. Instead they draw attention to the type description. They focus on the second phoric dimension in indefinite NPs, viz. type-identity, rather than instance nonidentity. More specifically, they convey that the new instance, despite being a different instance, shares the features that make up the type of the antecedent instance.

(28) Of the 202 complaints which the tribunal did act on, 36 related to fees and charges. "In some cases, the complaint is linked to alleged agent misrepresentation if the complainant believes that fees, charges or commissions were not accurately explained prior to the sale of superannuation policy," the report said. A similar common complaint was that people were sold policies which were not suited to their needs. (CB)

(29) Who is likely to take serious notice of subtle discrimination, as in the example of the small boy and the ice cream? But each patient's therapy reveals endless comparable examples. $(\mathrm{CB})$

(30) An 18-truck convoy carrying 23 tons of aid left Sarajevo to make the 90-mile trip. At the town of Vildeja, it ran into an organized demonstration of 150 women and children blocking the road. They said they 


\section{English Adjectives Expressing "Type-Anaphora”}

would not allow food to pass through to their enemies. Then they demanded half the food on board the convoy for themselves. The convoy leader, Larry Hollingworth, told them this was an attempt to hijack a relief convoy and he refused. He turned back and tried another route only to find his path blocked by an identical demonstration, this time orchestrated by two Serb women in uniform. (CB)

As the examples show, the postdeterminer uses signal type-phoricity in contexts that imply a more elaborate type specification than that provided by the head noun of the NP (and the antecedent NP) alone. They signal that the type description has to be "enriched" by features from the context. In examples such as (28) and more clearly (31) below, the additional features are expressed in the elaborate pre- and postmodification found in the NP itself.

(31) I'd love to visit the house in Scotland or, even better, love to read about similar stately homes cared for in such a way. (CB)

In examples such as (30), the features constitute the entire preceding discourse. The third possibility, illustrated in (29), is that they are only implied.

\section{Conclusion}

In this paper, I have fleshed out Davidse's $(1999: 228,2001)$ proposal that indefinite determiners, which signal type-identifiability, can be supplemented by a special set of postdeterminers that further clarify that the type is phorically retrievable in the form of an antecedent instance. This proposal was innovative in the literature on phoricity, which mainly focused on co-referentiality as prototypical phoric relation. First, I have refined Davidse's description of the notion of type-phoricity as a complex phoric relation encompassing both non-identity on the instance-level and identity on the type-level. Secondly, I have provided a detailed semantic study of nine adjectives that express type-phoricity in English and the subtle, but important, meaning differences between them. Viewed in a theoretical light, the analysis of type-phoricity presented here has shown that the mechanisms of indefinite determination and of phoric relations in the discourse are more complex than traditionally assumed. It also provides further support for the cognitive grammar tenet that the instance and type specifications are of equal importance in the identification of NP referents.

\section{References}

Bache, Carl. 2000. Essentials of mastering English: A concise grammar. Berlin/New York: Mouton de Gruyter.

Breban, Tine. 2002. Adjectives of comparison: Postdeterminer, epithet and classifier uses. M.A. diss., K.U.Leuven. 
Tine Breban

Breban, Tine. 2006. English adjectives of comparison: Lexical and grammaticalized uses. Ph.D. diss., K.U.Leuven.

Breban, Tine. 2008a. Towards a comprehensive definition of the 'postdeterminer' in English. Paper presented at ELC1, Santiago de Compostela, 10-11 May 2008.

Breban, Tine. 2008b. Secondary determiners as formal markers of generalized instantiation in English nominals. Paper presented at CSDL9, Cleveland, 1820 October 2008.

Breban, Tine. 2008c. The grammaticalization and subjectification of English adjectives expressing difference into plurality/distributivity markers and quantifiers. Folia Linguistica 42(2):259-306.

Breban, Tine, and Kristin Davidse. 2003. Adjectives of comparison: The grammaticalization of their attribute uses into postdeterminer and classifier uses. Folia Linguistica XXXVII(3/4):269-317.

Breban, Tine, and Kristin Davidse. 2008. The complex deictic semantics of the indefinite determiner + postdeterminer unit in English. Paper presented at ISLE 1 (First Triennial Conference of the International Society for the Linguistics of English), Freiburg, 8-11 October 2008.

Davidse, Kristin. 1999. The semantics of cardinal versus enumerative existential constructions. Cognitive Linguistics 10(3):203-250.

Davidse, Kristin. 2001. Postdeterminers: Their secondary identifying and quantifying functions. Preprint nr. 177. Department of Linguistics. K.U. Leuven.

Davidse, Kristin. 2004. The interaction of idenfication and quantification in English determiners. In Michel Achard and Suzanne Kemmer, eds., Language, culture and mind, 507-533. Stanford: CSLI Publications.

Diessel, Holger. 2006. Demonstratives, joint attention, and the emergence of grammar. Cognitive Linguistics 17(4):463-489.

Gundel, Jeanette K., Nancy Hedberg, and Ron Zacharski. 1993. Cognitive status and the form of referring expressions in discourse. Language 69:274-307.

Halliday, Michael A.K. 1994 [1985]. An introduction to functional grammar. Second Edition. [First Edition.] London: Arnold.

Halliday, Michael, and Ruqaiya Hasan. 1976. Cohesion in English. London: Longman.

Huddleston, Rodney, and Geoffrey K. Pullum. 2002. The Cambridge grammar of the English language. Cambridge: Cambridge University Press.

Langacker, Ronald W. 1991. Foundations of cognitive grammar. Volume II: Descriptive application. Stanford: Stanford University Press.

Langacker, Ronald W. 2004. Remarks on nominal grounding. Functions of Language 11(1):77-113.

Lyons, Christopher. 1999. Definiteness. Cambridge: Cambridge University Press.

Macmillan English Dictionary: Rundell, Michael et al., eds. 2002. Macmillan English dictionary. Oxford: Macmillan Education. 


\section{English Adjectives Expressing "Type-Anaphora”}

Martin, James R. 1992. English text: System and structure. Amsterdam/Philadelphia: John Benjamins.

Modjeska, Natalia N. 2003. Resolving other-anaphora. Ph.D. diss., University of Edinburgh.

OED: Murray, James A.H., Henry Brodly, W.A. Craigie, and C.T. Onions, eds., The Oxford English Dictionary. 1989 [1933]. Second Edition on CD-ROM Version 3.1.1. Oxford: Oxford University Press.

Salmon-Alt, Susanne. 2001. Référence et dialogue finalisé: De la linguistique à un modèle opérationnel. Ph.D. diss., Université Henri Poincaré, Nancy 1.

Sinclair, John et al., eds. 1990. Collins COBUILD English grammar. London: HarperCollins.

Willemse, Peter. 2005. Nominal reference-point constructions: Possessive and esphoric NPs in English. Ph.D. diss., K.U.Leuven.

Tine Breban

K.U.Leuven

Department of Linguistics

Blijde Inkomststraat 21 PO box 3308

3000 Leuven

Belgium

tine.breban@arts.kuleuven.be 